\title{
Estudando a Família em Desenvolvimento: Desafios Conceituais e Teóricos
}

\author{
Studying the Family in Development: \\ Conceptual and Theoretical Challenges \\ El Estudio de la Familia en Desarrollo: \\ Desafíos Conceptuales y Teóricos
}
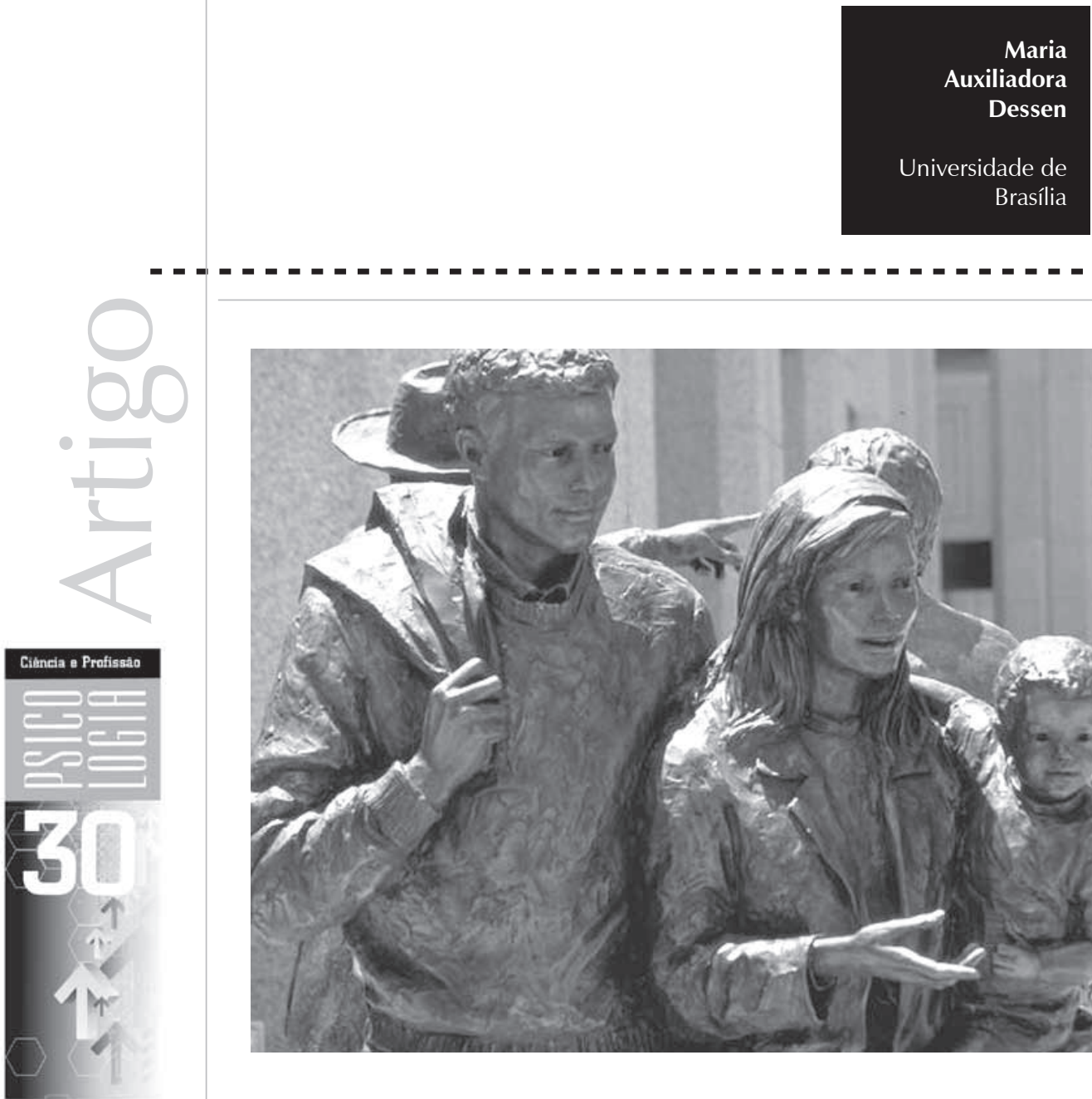
Resumo: Estudar a família em desenvolvimento em contextos sociais e culturais em constantes transformações constitui um desafio para os pesquisadores da área de Psicologia do desenvolvimento familiar. Este artigo tem como objetivo descrever o contexto em que viviam as famílias brasileiras quando o Questionário de Pai Ideal foi aplicado a jovens universitários participantes da pesquisa de Pasquali. São destacadas a estrutura e as relações parentais e de gênero que caracterizaram as famílias na segunda metade do século XX. A teoria sistêmica e a definição ecopsicológica de família são apontadas como caminhos promissores para orientar as pesquisas sobre o funcionamento familiar e as concepções atuais de família, mãe e pai.

Palavras-chave: Família. Teoria sistêmica da família. Relações parentais. Concepções de pai e mãe.

Abstract: Studying the family in development in social and cultural contexts that are in constant transformation constitutes a challenge for the psychologists who study the family development. This article aims to describe the environment in which Brazilian families lived when the Questionnaire of Ideal Father was administrated to young university students from Pasquali's research. The structure and the parental and gender relations that characterize the families in the second half of the XX century are highlighted. The sistemic theory and the family ecopsychological definition are pointed out as promising ways to guide the research about the family functioning and the current conceptions of family, mother and father.

Keywords: Family. System theory of family. Parental relations. Conceptions of father and mother.

Resumen: Estudiar a la familia en desarrollo en contextos sociales y culturales en constantes transformaciones constituye un desafío para los investigadores del área de la Psicología del desarrollo familiar. Este artículo tiene como objeto describir el contexto en el cual vivían las familias brasileñas cuando el Cuestionario de Padre Ideal ha sido llevado a cabo en jóvenes universitarios participantes de la investigación de Pasquali. Se destacan la estructura y las relaciones parentales y de género que caracterizan a las familias en la segunda mitad del siglo XX. La teoría sistémica y la definición ecopsicológica de familia son apuntadas como senderos promisorios para orientar las investigaciones acerca del funcionamiento familiar y las concepciones actuales de familia, madre y padre.

Palabras clave: Familia. Teoría sistémica de la familia. Relaciones parentales. Concepciones de padre y madre.

Estudar a família não é tarefa simples. Há 30 anos, ao investigar as concepções de pai e de mãe ideais de jovens universitários brasileiros, na tentativa de responder à pergunta "o que os filhos esperam que o pai seja?", Pasquali (1980) já reconhecia a complexidade dessa tarefa. Desde então, muita coisa mudou, não só nas sociedades ocidentais contemporâneas e, em consequência, na estrutura e no funcionamento das famílias, como também nos modos de pesquisar. A percepção dos 98 jovens universitários ( 25 do gênero masculino e 73 do gênero feminino), provenientes de famílias com pais vivos, em sua maioria, com mães que trabalhavam no lar e pais que eram funcionários públicos ou profissionais liberais (professores, comerciantes, engenheiros), reflete, claramente, a concepção da família nuclear tradicional das décadas de 60 e 70.

Em seu estudo, a medida das atitudes dos filhos em relação aos pais que gostariam de ter foi coletada na efervescência das transformações nas famílias que caracterizaram a segunda metade do século XX. Que mudanças foram essas que tiveram impacto nas relações familiares e, em decorrência, nas percepções que as pessoas tinham de seus pais e de suas mães e da própria família? Que avanços teóricos e conceituais marcaram a segunda metade do século $X X$, no que tange aos estudos sobre a família? Esses avanços tiveram repercussão na prática de pesquisa? A leitura do artigo de Pasquali suscita não somente essas, mas uma infinidade de outras questões que continuam muito atuais na agenda de pesquisadores da área de Psicologia da família.

Assim, a primeira seção deste artigo apresenta um panorama do contexto, da estrutura e das relações parentais e de gênero que marcaram as famílias brasileiras da segunda metade do século XX. Ênfase é dada às principais mudanças ocorridas nas sociedades ocidentais contemporâneas que tiveram 
impacto na estrutura e no funcionamento das famílias e nas concepções das pessoas sobre família, mãe e pai. A segunda seção trata, brevemente, dos avanços teóricos e conceituais no estudo das famílias. São enfatizadas as contribuições da abordagem sistêmica da família, bastante divulgada na década de 80, e a importância de se adotar o conceito ecopsicológico de família no planejamento de pesquisas sobre família. A terceira e última seção é dedicada à discussão da necessidade de investigações sobre as atuais concepções de família, pai e mãe para a compreensão da família. Investigar as dimensões das relações familiares, como intimidade, proteção e autoridade, medidas pelo Questionário de Pai Ideal - QPI, constituem temas promissores de pesquisa.

\section{As famílias brasileiras na segunda metade do século $X X$}

A diversidade étnico-cultural do Brasil, formada pela mistura de imigrantes europeus, escravos africanos, povos nativos (índios) e tantos outros, impõe diferenças, muitas vezes regionais, de estruturas, costumes e tradições às famílias (Nolasco, 2001; Torres \& Dessen, 2007). A evidência de que não há, no País, um modelo único de organização familiar nos leva a utilizar o termo famílias brasileiras em vez de família brasileira (Biasoli-Alves, 1997; Dessen \& Biasoli-Alves, 2001; Dessen \& Torres, 2002; Neder, 1998; Torres \& Dessen, 2007). Além da diversidade étnicocultural, outro fator se mostra fundamental para a compreensão do funcionamento familiar: as mudanças relevantes no contexto e na estrutura e funcionamento das famílias brasileiras. Como viviam as famílias de origem dos jovens universitários da década de 70 que participaram da pesquisa de Pasquali? Em que contextos esses jovens constituíram as suas próprias famílias, nas décadas seguintes?

\section{O contexto, a estrutura familiar e os papéis de gênero nas famílias brasileiras}

A década de 50 e o início da década de 60 foram marcados pela continuidade do movimento de nuclearização da família que caracterizou as duas décadas precedentes. No período de 1920 a 1940, predominava a família nuclear, com muitos filhos, havendo uma hierarquização clara nas relações familiares e uma divisão de tarefas em função do gênero (Vaitsman, 1994; Vieira, 1998). De acordo com esses autores, a explosão do capitalismo industrial, particularmente em 1930, e a coexistência de realidades predominantemente agrárias e do movimento crescente de êxodo rural influenciaram a composição e os modos de vida familiar desse período. Portanto, a família da primeira metade do século XX já era caracterizada como a família da modernidade (Almeida, 1987).

$\mathrm{Na}$ década de 50, as famílias eram constituídas basicamente por pai, mãe e filhos que obedeciam ao pai, econômica e afetivamente. "Esse novo arranjo familiar consolidava definitivamente o espaço privado e o individualismo" (Galano, 2006, p. 124). Além disso, devido à nova tendência de diminuição do número de descendentes, a partir dos anos 50 e começo dos anos 60, os casais passaram a ter uma média de três a quatro filhos, diferindo da geração anterior, que tinha muitos filhos (Monteiro, 1998).

No âmbito das relações sociais, começava uma nova participação social da mulher, com a ascensão do movimento feminista, a revolução técnico-científica e o desenvolvimento acelerado de novas ciências, especialmente as humanas (Trindade, 2001). Esses eventos ganharam espaço e foram aos poucos conquistando o pensamento social nessas décadas, especialmente no que diz respeito 
Na década de

50 , as famílias eram constituídas basicamente por pai, mãe e filhos que obedeciam ao pai, econômica e afetivamente. "Esse novo arranjo familiar consolidava definitivamente 0 espaço privado e o individualismo" (Galano, 2006, p. às mulheres (Vaitsman, 1994). Obviamente, as repercussões foram inegáveis para a divisão de papéis sexuais, tanto no espaço público quanto no espaço privado, incluindo o da família (Chaves, 2006). Neste último, a mulher ainda mantinha seu papel exclusivamente voltado para a maternidade, sendo rigorosa no cuidado da casa e na educação dos filhos, complementando o papel do pai, que era quem exercia a autoridade e se responsabilizava pelo sustento financeiro do lar (Simionato-Tozo \& Biasoli-Alves, 1998).

Com o objetivo de investigar as transformações da família ao longo do tempo na perspectiva de diferentes gerações, Cerqueira-Silva, Oliveira e Dessen (2010) entrevistaram 12 pessoas com idades entre 26 e 82 anos. Sobre a década de 50, relataram: "A família da época era a família dominada pelo pai. A palavra do pai, realmente, era a mais importante da família. Ele era o provedor e o orientador, determinava todas as ações da família. A mãe ficava mais dentro de casa, o papel da mãe era cuidar da casa e dos filhos. E o pai, além de provedor, era o baluarte moral que todos os filhos seguiam!" (B.E., 53 anos, sexo feminino). Em outras palavras, "O pai mandava na família" (R.A., 53 anos, sexo feminino), e, "Naquela época, era muito mais comum os pais trabalharem e as mães cuidarem dos afazeres de casa, dos filhos" (E. V., 51 anos, sexo masculino). Esses relatos sobre o funcionamento real da família e das percepções de pai e mãe foram feitos por pessoas que eram os jovens que viviam na década de 70, por ocasião da aplicação do Questionário de Pai Ideal - QPI, no estudo de Pasquali. Esses relatos ilustram o contexto real da época, permitindo, assim, melhor compreensão do conceito de Pai Ideal e de Mãe Ideal expresso pelos jovens universitários de sua amostra. Para eles,

o pai ideal apresenta uma figura bastante complexa, integrando simultaneamente, e em alto grau, valores pessoais de conhecimento e domínio sobre a natureza bem como de valores de relacionamento humano que fazem dele o amigo respeitador e protetor da pessoa humana. Nesse contexto não entra o domínio sobre os outros seres humano (autoridade) como um valor desejável num pai ideal. (Pasquali, 1980, p. 184)

A mãe, por sua vez, é idealmente concebida em termos de valores que uma pessoa deve possuir, como:

um ser humano dotado de habilidade
intelectual, de ação, realismo e auto-
confiança. Uma mãe, enfim, representando
uma pessoa que se define em seus próprios
termos de ser racional e de ação (homem
racional e homo faber), e não em termos
de sua função procriadora. (Pasquali, 1980,
p. 188)

Essa concepção de mãe foi rotulada por Pasquali de moderna, por representar reivindicações dos movimentos feministas e de liberação sociocultural da mulher. Foi por meio de uma pequena minoria delas, aquela de classes sociais mais favorecidas em termos de renda e status, que começou a integração da mulher no sistema educacional universal, isto é, de segundo e terceiro graus (Vaitsman, 1994). Essas estudantes começaram a ter, então, oportunidades para prosseguir os estudos após se formarem como professoras primárias na década de 50, mesmo que dando continuidade a carreiras tipicamente femininas: magistério de nível superior, pedagogia e enfermagem.

Com relação ao estado civil dos genitores das famílias das décadas de 50 e 60, a maioria era casada, e, embora as mães continuassem trabalhando em casa e o pai no ambiente profissional, os primeiros indícios de uma nova participação social da mulher começavam a surgir (Vaitsman, 1994). De acordo com esse autor, as mães que começavam a trabalhar fora do lar exerciam atividades de cuidado e educação de terceiros, condizentes com as profissões femininas que emergiam nessas 
décadas. Nesse contexto, a religião (católica) tinha um papel importante, sobretudo para a manutenção dos valores vigentes, e o discurso da religião confirmava e enfatizava o discurso da própria família (Biasoli-Alves, 2000).

Embora tenham ocorrido algumas importantes e decisivas transformações no papel feminino, foi somente no final da década de 60 que o papel da mulher se modificou expressivamente, com mudanças evidentes na família (Dessen \& Braz, 2005a).

Diferindo das décadas precedentes, o final dos anos 60 e as décadas de 70 e 80 foram marcadas não só pela participação ativa das mulheres no contexto social, político e econômico do País mas também por relações mais igualitárias entre os cônjuges e entre pais e filhos (Dessen \& Torres, 2002). Nessa época, os movimentos feministas, hippies, homossexuais, estudantis, ecológicos e negros ganharam força representativa, evidenciando um momento de transformações na vida social e privada, especialmente quanto à maior igualdade de papéis entre homens e mulheres, à maior volatilidade das relações afetivas e à ampliação das escolhas sexuais, dentre outras questões (Galano, 2006). As mães, mesmo iniciando a sua vida profissional fora do lar, carregavam o compromisso com a educação dos filhos, o que implicava, assim, uma dupla jornada de trabalho, mesmo quando podiam contar com a ajuda de terceiros (Santos, Caldana, \& Biasoli-Alves, 2001).

A estrutura familiar do final dos anos 60 até os anos 80, por sua vez, sofreu uma diminuição significativa no número de filhos, que passou de três a quatro filhos para dois a três, em média. Três fatores foram de especial influência nessa mudança: (a) a entrada da mulher no mercado de trabalho, (b) a crise econômica dos anos 80 e (c) o surgimento de novos valores de criação dos filhos (Ribeiro, Sabóia, Branco, \& Bregman, 1998). Segundo
Petrucelli (1998), outros fatores também contribuíram para as mudanças: a difusão da pílula anticoncepcional, a regulamentação do divórcio, a baixa fecundidade, o aumento no nível da escolaridade feminina bem como sua maior possibilidade de acesso à informação (Monteiro, 1998). Concomitantemente a esses fatores, houve um aumento no número de casais sem filhos e de uniões consensuais.

No âmbito das relações familiares, as principais mudanças ocorridas entre as décadas de 50 (família hierárquica) e 80 (família igualitária) foram: (a) homem e mulher passam de uma posição de diferentes, em termos de papéis e autoridade, para uma posição de identidade idiossincrática, (b) as relações parentais passam de extremamente hierarquizadas para mais igualitárias, (c) a identidade calcada na posição, sexo e idade da pessoa, com a autoridade paterna inquestionável, passa a ser baseada mais nas diferenças pessoais do que nas sexuais, etárias e posicionais, dando início à chamada crise da autoridade na família, e (d) a família passa de uma rede mais extensa para uma mais nuclearizada, fragmentada e privatizada (Vieira, 1998). Essas mudanças indicam menor desigualdade entre os papéis masculinos e femininos, o que implica menor hierarquização dentro da instituição familiar e mudanças na distribuição das tarefas do lar entre os genitores (Deutsch, 2009).

O início dos anos 90 começou, portanto, fortemente marcado pelas profundas transformações ocorridas na década de 80 . O divórcio teve seus índices aumentados significativamente, em até três vezes, nos anos 90, fato que repercutiu decisivamente nas novas configurações familiares. Aproximadamente $47 \%$ dos domicílios passaram a se organizar na ausência de, pelo menos, um dos pais, crescendo a incidência de novos arranjos, embora o modelo nuclear de família ainda continuasse sendo maioria (Pereira, 2003). Novas configurações de 
O modelo de família nuclear ainda é, também, dominante em países como os do norte europeu, os Estados Unidos e o Canadá (Georgas, 2003). famílias surgiram - as monoparentais e as cangurus - as primeiras constituídas por apenas um dos cônjuges e os filhos, e, as segundas, por um dos cônjuges e seus filhos que voltaram a morar com os pais (Galano, 2006; Pereira, 2003).

As formas alternativas de convivência familiar passaram, nessa década, a ser cada vez mais frequentes, em um cenário social marcado por reformulações constantes de projetos, vontades e aspirações individuais (Gomes \& Resende, 2004). Essas novas configurações familiares refletiam o efeito dos novos valores, crenças e práticas sociais assumidos, que resultaram tanto em aumento de divórcios quanto em recasamentos. Embora tenha diminuído o percentual de domicílios habitados por casais com filhos de 57,4\% para 49,4\%, entre os anos 1996 e 2006, esse ainda constitui o maior grupo entre os arranjos familiares brasileiros (Instituto Brasileiro de Geografia e Estatística [IBGE], 2007). O modelo de família nuclear ainda é, também, dominante em países como os do norte europeu, os Estados Unidos e o Canadá (Georgas, 2003).

Nesse período, as funções de cuidado e socialização dos filhos passaram a ser compartilhadas com outros grupos sociais, de acordo com as suas possibilidades econômicas. Na esfera das relações familiares, o pai continuava desempenhando a função de prover o sustento material, embora compartilhando cada vez mais essa função com as mães, assim como algumas tarefas relacionadas ao cuidado das crianças (Dessen \& Braz, 2000a). No entanto, "a divisão de tarefas domésticas, a criação e a educação dos filhos parecem não acompanhar de maneira proporcional as mudanças decorrentes da maior participação da mulher no mercado de trabalho e do sustento econômico do lar" (Wagner, Predebon, Mosmann, \& Verza, 2005, p. 182).
As intensas transformações no papel feminino enfraqueceram a relevância do modelo tradicional nuclear de família e provocaram outras mudanças, tanto no contexto brasileiro (Dessen \& Torres, 2002; Neder, 1998; Petrucelli, 1998; Singly, 2000) como em outros países (Petzold, 1996). As mudanças ocorreram, particularmente, nos hábitos de alimentação, decorrentes do estilo de vida moderna, sobretudo das cidades urbanas de porte médio e grande, em que as famílias estão, cada vez mais, participando de arranjos complexos em que o transporte e os cuidados das crianças são compartilhados com outras famílias (Stratton, 2003) ou com empregadas domésticas e terceiros, no caso do Brasil. Evidentemente, não estamos nos referindo aqui às famílias brasileiras pobres ou que vivem abaixo da linha da pobreza, cuja dinâmica de relações é muito diferente daquelas de classe média (Torres \& Dessen, 2007). Essas modificações foram e continuam sendo fortemente diferenciadas pelas condições sociais, econômicas e políticas de cada Região brasileira (Ribeiro et al., 1998).

Como essas mudanças no contexto, na estrutura familiar e nos papéis de gênero influenciaram os processos de socialização das famílias brasileiras e os papéis de mãe e de pai?

\section{O que mudou nas relações parentais e nos papéis de mãe e de pai nas famílias brasileiras, a partir dos anos 80 ?}

Há 30 anos, quando o Questionário de Pai Ideal-QPI foi aplicado a jovens universitários, a maioria proveniente de famílias com pais casados legalmente e com mães que não exerciam atividades fora do lar, a grande mudança foi mesmo no papel da mulher. E as crescentes mudanças nos papéis 
femininos afetaram significativamente os papéis masculinos (Henderson, Tickmyer, \& Tadlock, 2005). Em decorrência disso, toda a dinâmica familiar foi modificada: marido e mulher passaram a compartilhar mais as tarefas domésticas e os cuidados com os filhos, conforme relatado no estudo de Cerqueira-Silva et al. (2010):

\begin{abstract}
Nossa..., contar histórias pro G. (filho) é só ele (o pai). Adora! Toda noite ele vai lá e fica horas!... E a mamadeira do G. é ele quem faz também, sabe? O G. fala que a dele é mais gostosa (risos). Ele adora cozinhar também. Chega fim de semana e é só ele na cozinha. Chama os amigos, faz aquela festa! (A. O., sexo feminino, 38 anos)
\end{abstract}

À medida que a hierarquia familiar se tornava mais flexível na direção de maior igualdade de papéis entre os genitores, as relações maritais e parentais também se modificavam (Dessen \& Braz, 2005b), particularmente quanto aos valores relativos à educação e ao processo de socialização dos filhos (Dessen \& Torres, 2002; Kreppner, 1992; Zamberlan \& Biasoli-Alves, 1997). Na primeira metade do século XX, por exemplo, as crianças eram consideradas passivas e eram socializadas de forma a valorizar a submissão infantil aos adultos, conforme relato a seguir: "Se às vezes papai comprava... um exemplo, né? Um vestido! E a gente num queria aquele vestido, queria outro vestido! Papai comprava aquele que ele escolhia" (L.U., 71 anos, sexo feminino). As vontades e as opiniões dos adultos prevaleciam na relação, havendo abertura mínima para negociações. Como salienta Biasoli-Alves et al. (1997), naquele tempo, era comum o uso de práticas coercitivas, especialmente punitivas: " $E$ quando a gente 'cumetia' alguma coisa longe dele, na hora que chegava, apanhava! Ele num perdoava assim... Corrigia mesmo na base da surra, né?", "Antigamente era na base da chibata, né?" (J. O., 75 anos, sexo masculino).

As crianças, nas décadas de 50 e 60, continuaram assimilando o valor respeito como positivo e vinculado às práticas coercitivas e ao medo, o que explica, em parte, a reprodução desses modelos parentais ao longo de gerações. O uso de práticas punitivas na educação dos filhos, especialmente meninos, sempre que se portavam incorretamente, era mais frequente por parte da figura paterna da família. O pai era concebido como aquele que impunha a ordem, de acordo com o papel de gênero vigente naquele período: "Eu fui criado com a obediência cega às determinações de meu pai. A minha forma de criação é que tinha uma orientação a ser seguida mais autoritária e absolutista do pai" (B. E., 53 anos, sexo masculino).

Em consonância com os resultados do QPI (Pasquali, 1980), a maioria dos entrevistados do estudo de Cerqueira-Silva et al. (2010), que eram crianças nas décadas de 50 e 60, referiu-se às práticas coercitivas com pesar, conferindo, hoje, outro sentido ao conceito de respeito: "Ao contrário do meu pai e minha mãe que eu obedecia por medo, ela (filha) me obedece por respeito" (R.L., 53 anos, sexo feminino). "Hoje em dia, o jovem argumenta com o pai, com a mãe... Fala não, eu num gosto, eu não quero, eu não vou" (L.U, 71 anos, sexo feminino).

Diferentemente das décadas anteriores, a mãe passou a questionar, com frequência, o excesso de rigidez, o autoritarismo, o nível de exigência e a punição que fizeram parte da sua educação, indicando o quanto era importante mudar a forma de agir com os filhos (Biasoli-Alves, 2000). Essa nova postura materna evidencia uma mudança significativa na concepção de ser boa mãe ao longo do século XX, que passou de práticas controladoras de comportamento, no início do século, para a demonstração de ternura e estimulação do comportamento, ao final da década de 60, para, em seguida, valorizar o diálogo e o bem-estar subjetivo do filho, nas décadas de 70 e 80 (Biasoli-Alves, 1997, 2000). 
Quanto ao papel do pai, este continuou sendo visto como figura afetivamente distante dos filhos, que mantinha uma relação caracterizada mais pelos cuidados dispensados no âmbito da educação e da saúde, conforme ilustrado a seguir:

O meu pai ocupava a posição de provedor do lar, e sua alta exigência contribuiu para que a gente sentisse medo e insegurança para se comunicar com ele. Além disso, algumas informações a respeito do meu pai vinham através do olhar da minha mãe, que às vezes facilitava situações de aproximação e em outras, acabava, por nos afastar dele. (P. A., 32 anos, sexo feminino)

Para Gomes e Resende (2004), o pai é lembrado como alguém que se mantinha distante, despojado de qualquer possibilidade de relação mais íntima, havendo destaque para o afeto materno. Além de não haver a procura por maior participação do pai, a mãe, ao mesmo tempo em que era a mediadora da relação entre o pai e o filho, também se interpunha como obstáculo ao afeto entre eles.

Na década de 90, os filhos se tornaram mais participativos nas decisões familiares, e o diálogo, o respeito e o afeto se tornaram predominantes na relação parental (Arriagada, 2000; Cerveny \& Berthoud, 1997; Pereira, 2003). "Em termos de disciplina, o recurso que passou a ser mais utilizado foi o diálogo, numa prática caracterizada pelo uso de técnicas disciplinares verbais, preferencialmente, não punitivas" (Wagner, Predebon, \& Falcke, 2005, p. 96). A família passa a ser considerada um refúgio mais atraente para os filhos, que nela permanecem mais tempo (Pereira, 2003). Com relação a essa questão, é importante destacar que a maior permanência dos filhos em casa se deve, também, à questão econômica, isto é, ao aumento da pobreza, da desigualdade social e das dificuldades de acesso ao mercado de trabalho (Arriagada, 2000).
Apesar de terem ocorrido diversas mudanças nas interações e relações familiares e, em consequência, um aumento da igualdade e do equilíbrio entre marido e mulher no âmbito das famílias no cenário internacional (Deutsch, 2009), os padrões tradicionais de gênero ainda se mantêm (Dessen \& Braz, 2000; Wagner \& et al., 2005). Nesse sentido, a seguinte fala é bem ilustrativa:

Porque o F. (marido) é muito machão, sabe? Daqueles assim muito... muito tradicionais, né? Que ele num vê meu trabalho como um trabalho, ele vê como um... um... um passatempo. Pra ele é tipo uma coisa que a mulher pode fazer pra se ocupar enquanto o marido tá fora, trabalhando, fazendo dinheiro mesmo, sabe? Mas aí, na hora que ele chega, a esposa tem que tá em casa, lindinha, cheirozinha, esperando ele.... É, os cuidados da F. (filha) é mais eu mesma, sabe? O F. (marido) num participa muito não, até porque ele num fica muito em casa, trabalha muito. Aí quando ele tá, ele prefere ficar na dele, lendo, vendo TV no quarto. (C. G., 42 anos, sexo feminino)

Para Wagner et al. (2005), a estrutura familiar tradicional, com o pai como único provedor e a mãe como única responsável pelas tarefas domésticas e pelo cuidado com os filhos, está passando por um período de transição na cultura brasileira de classe socioeconômica média. Entre as mulheres brasileiras profissionalmente ocupadas em 2005, 92\% declararam ao IBGE (2006) também cuidarem de afazeres domésticos. Apesar de um aumento na participação dos homens, atualmente, ainda pouco mais da metade $(51,4 \%)$ realiza esses afazeres (IBGE, 2007), portanto, muitas famílias brasileiras contemporâneas, apesar de passarem por mudanças, ainda apresentam uma hierarquia que se reflete na divisão de tarefas ditas masculinas e femininas (Torres \& Dessen, 2007).

A participação do pai, mesmo que não proporcional à da mãe, é uma tendência evidente desde o início dos anos 90 (Lewis 
\& Dessen, 1999), fato esse constatado pelas concepções ideais de pai e de mãe das décadas de 70 e 80 descritas por Pasquali. "Os valores acham-se entranhados na cultura e sua assimilação é lenta, constante e profunda, de tal modo que transformações drásticas levam muito tempo para se efetivarem" (Biasoli-Alves, 2000, p. 239). A socialização da criança brasileira foi fortemente marcada pelas tradicionais relações de gênero, geralmente cabendo aos meninos a formação que visa à produção e, em decorrência disso, o sustento da sua futura família, e às meninas, o aprendizado de habilidades e conhecimentos que fizessem delas boas candidatas ao casamento:

Éramos educadas para sermos mães de família. Exatamente isso! Dona de casa e mãe de família. Geralmente as mocinhas estudavam só um pouquinho, depois aprendiam os trabalhos manuais, cozinha, bordado também. Eram preparadas para obedecerem ao marido, para cuidarem da casa, para o casamento e para a família. (M. A., 82 anos, sexo feminino)

Dos resultados apresentados por Pasquali, merecem destaque aqueles que mostram "a tendência ao desaparecimento da concepção de cada uma das figuras parentais como pólos opostos de valores masculinos e de valores femininos" (p. 189) em seus ideais, em seu imaginário. Destaco, particularmente, a qualidade de habilidade mental se contrapondo à concepção de inferioridade intelectual da mulher, fatores que se opunham, obviamente, à definição de mãe aceita no passado, conforme comenta Pasquali em seu artigo. Será que a concepção de mãe etiquetada como moderna no auge do movimento feminista e de liberação sociocultural da mulher, que caracterizou as décadas de 60 e 70, em diferentes países, permanece no presente? Em outras palavras, será que as concepções de pai ideal e de mãe ideal dos jovens das décadas de 70 e 80 se transformaram no pai real e na mãe real dos dias atuais?
Não se pode afirmar que a família do passado seja melhor ou pior que a família do presente; é preciso compreendê-la sob o ponto de vista de um contexto social, histórico e cultural em constante transformação, traçando trajetórias probabilísticas tanto para o indivíduo quanto para o grupo familiar. Os membros de determinadas famílias e culturas precisam se adaptar às demandas e tarefas propostas pelos contextos nos quais estão inseridos, uma vez que cada família possui seus próprios padrões de comunicação, que, por sua vez, influenciam as experiências de seus membros (Kreppner, 2000, 2003). Isso nos remete à questão: que dimensões das relações familiares devemos priorizar, de modo a garantir uma compreensão dos modos de funcionar das famílias? Os fatores, ou dimensões, priorizados por Pasquali no Questionário de Pai Ideal - QPI, a saber: intimidade, proteção, autoridade, realismo, sabedoria, dinamismo e ação, poder e feminilidade continuam sendo dimensões importantes para a compreensão do funcionamento familiar. $\mathrm{O}$ fator intimidade, por exemplo, que foi particularmente reivindicado pelos filhos como característica de um pai ideal, constitui a base da maior parte das definições de família que embasam as pesquisas atuais.

Como a percepção de família e dos papéis de mãe e pai, sejam eles papéis ideais ou reais, é influenciada pelas alterações na estrutura e na dinâmica das relações familiares, isso nos leva não só a questionar o conceito de família, e as ideias de normalidade relacionadas a ela, mas também a tentar compreendê-la como um sistema complexo, influenciado por múltiplos fatores e eventos internos e externos, que sofre variações em função dos contextos cultural, social e histórico em que está inserida. 
Avanços conceituais e teóricos no estudo da família

O processo de pesquisar, por sua própria natureza, envolve inúmeras decisões por parte do pesquisador, que se defronta com questões conceituais, teóricas e metodológicas. Em se tratando dos estudos com famílias, a primeira questão básica que devemos formular é: o que é família? Devemos, portanto, refletir sobre qual ou quais conceitos de família adotar na pesquisa científica. Em segundo lugar, devemos nos perguntar: o que significa, afinal, ser mãe, pai e irmão no contexto dos participantes da pesquisa? Além das questões conceituais, nós nos deparamos com um grande desafio relacionado às questões teóricas. Que perspectivas teóricas são mais apropriadas para orientar os pesquisadores de famílias? Obviamente, essas questões conceituais e teóricas têm impacto no planejamento de nossas pesquisas e na metodologia que adotamos para investigar as concepções e os padrões de comunicação na família.

\section{Questões conceituais: desafios para uma definição da família contemporânea}

As abordagens contemporâneas no estudo da família têm definido seu objeto com base na premissa de que são diversos os tipos e as possibilidades de família nos tempos atuais. Arranjos familiares como pessoas solteiras que vivem sozinhas, cônjuges não casados que habitam a mesma casa, o casamento experimental ou a convivência temporária antes da tomada de decisão de oficializar o casamento, os casais homossexuais, as famílias recasadas, os cônjuges que moram em casas diferentes e as pessoas que vivem com parentes que exigem cuidados são todas construções de vida familiar baseadas, principalmente, nos sentimentos subjetivos nutridos pelas pessoas envolvidas.

Uma definição contemporânea de família, portanto, deve estar baseada na opinião de seus membros, considerando a afetividade e a proximidade com os entes queridos critério para a composição de família. Variáveis como consanguinidade, continuidade ao longo da vida, relacionamento heterossexual, divisão da mesma casa, etc., por si só, não definem o que seja família. Petzold sintetiza, então, os diferentes arranjos que caracterizam as sociedades ocidentais contemporâneas, agrupando-os na proposição de um conceito abrangente de família, por ele denominado definição ecopsicológica. Segundo esse autor, "uma família é um grupo social especial, caracterizado por relações íntimas e intergeracionais entre seus membros" ( $p$. 39). Os familiares são aqueles com os quais mantemos um vínculo baseado na intimidade e nas relações intergeracionais.

Essa visão incorpora também variáveis externas, características das relações entre os cônjuges, entre genitores e filhos e com outras pessoas que podem fazer parte da família bem como aspectos próprios dos sistemas ecológicos propostos por Bronfenbrenner (1979/1996): o macro, o exo, o meso, o micro e o cronossistema, embora Petzold não tenha feito referência a Bronfenbrenner. Combinando todas essas variáveis, Petzold propõe a existência de 196 tipos de famílias convivendo nas sociedades ocidentais contemporâneas. Na perspectiva do macrossistema, há quatro grupos de fatores que podem influenciar a caracterização de uma família: se os casais são ou não legalmente casados, se o arranjo de seus relacionamentos é vitalício ou temporário, se os rendimentos e ganhos de cada um dos cônjuges são compartilhados 


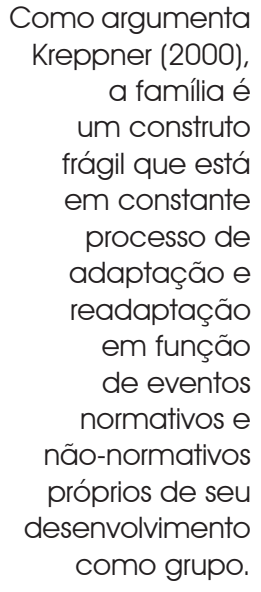

ou separados e se eles habitam a mesma residência ou têm moradias separadas. No exossistema, que envolve contextos e redes sociais específicos, a influência é verificada pelo tipo de relação estabelecida entre os membros familiares, isto é, se a relação ocorre com base nos laços sanguíneos ou no casamento, se os membros são autossuficientes ou dependentes de cuidado, se são economicamente dependentes ou independentes e se compartilham ou não uma mesma cultura. O mesossistema envolve três variáveis: a presença ou a ausência de filhos, o fato de as crianças serem filhos naturais ou adotivos e o tipo de relação parental, ou seja, se a figura parental é biológica ou não. Por fim, três são os possíveis aspectos que compõem o microssistema, que é definido do ponto de vista da relação diádica estabelecida entre os genitores: se o estilo de vida é compartilhado ou separado, se a relação estabelecida é hetero ou homossexual e se o padrão de interação é igualitário ou dominante-subordinado.

Zamberlan e Biasoli-Alves (1997) também apresentam uma concepção semelhante no que tange à ênfase nas relações interpessoais. Segundo elas, a família é um grupo primário mantido pelo parentesco e pelas relações interpessoais entre os familiares, as quais são sustentadas por afeição, apoio, partilha de tarefas domésticas, cuidados com a prole e cooperação mútua em várias outras atividades. A família é, também, definida por um tipo especial de relação - as relações intergeracionais - entre, pelo menos, pai ou mãe e seu filho (Kreppner, 2000, 2003); nesse caso, a família é constituída pelas relações e pela transmissão de padrões de uma geração para outra.

Considerando que a família vem sofrendo o impacto de diversas mudanças estruturais, sociais e culturais nos últimos tempos, conceituá-la e/ou encontrar consenso sobre sua definição tornou-se uma tarefa difícil. No entanto, não podemos negar que "a família ainda continua sendo uma instituição forte e de influência, mas um pouco mais complexa e flexível do que as imagens do passado nos levariam a pensar" (Stratton, 2003, p. 337). De acordo com esse autor, independentemente da diversidade de tipos de famílias que caracterizam as sociedades ocidentais contemporâneas, a tendência de manter um compromisso e o suporte social e econômico entre os membros de uma família, visando a fornecer uma infraestrutura para o desenvolvimento dos filhos, permanecem enraizados.

Como argumenta Kreppner (2000), a família é um construto frágil que está em constante processo de adaptação e readaptação em função de eventos normativos e não normativos próprios de seu desenvolvimento como grupo. Nesse grupo, todos os membros familiares são participantes ativos nas relações, sendo as influências exercidas entre eles mútuas e bidirecionais. Em consequência, estudar a família envolve, necessariamente, estudar os processos de comunicação e as interações e relações existentes entre os seus membros, levando em consideração as tarefas de desenvolvimento não só do indivíduo mas também do grupo familiar que constitui a unidade mínima de análise. Como estudar a família em desenvolvimento em um contexto também em desenvolvimento?

\section{Questões teóricas e metodológicas: contribuições de modelos sistêmicos para o estudo da família}

Segundo Kreppner (2003), durante as décadas de 40 e 50, 
novos conceitos baseados na teoria dos sistemas, na cibernética e na teoria da informação, em combinação com velhas abordagens, como a teoria psicanalítica, formaram uma perspectiva inteiramente nova sobre a complexidade e reciprocidade do comportamento humano e seu desenvolvimento dentro da rede de relações e da cultura da comunicação dentro da família. (p. 202)

A teoria sistêmica da família, amplamente divulgada na década de 80 por Minuchin (1988), trouxe um novo olhar para os estudos sobre família. Adotar a concepção sistêmica significa focalizar a família como um sistema complexo, composto por vários subsistemas que se influenciam mutuamente: maridoesposa, genitores-filhos, irmãos-irmãos, avósnetos (Dessen, 1997; Kreppner, 1992, 2000). De acordo com Kreppner (2000), a influência da relação conjugal no desenvolvimento dos filhos ocorre, principalmente, por meio da qualidade da comunicação estabelecida entre os cônjuges, que não só é revelada mas que também influencia as trocas comunicativas com os filhos nas mais diversas situações. Os padrões de comunicação conjugal e parental desenvolvidos em uma determinada família servem, então, de modelo para os filhos, que tendem a reproduzi-los na formação de um novo ciclo familiar. A meta-análise de Erel e Burman (1995) mostra evidências contundentes da influência da relação marital no bem-estar da criança e sugere que a satisfação marital é fator preditivo de uma boa saúde física e emocional dos filhos, enquanto as tensões na relação conjugal produzem um mau funcionamento na relação genitores-criança.

Esses subsistemas são separados por fronteiras e constituídos por regras e limites próprios que regulam as trocas e os intercâmbios estabelecidos entre eles, o que permite a manutenção de sua integridade e de seus padrões próprios. A falta ou o afrouxamento exacerbado dessas fronteiras e desses limites pode caracterizar a patologia em um sistema familiar (Minuchin, 1988). De acordo com essa autora, a evolução e a mudança inerentes aos sistemas abertos representam as transformações ocorridas ao longo do tempo no ciclo de vida da família, em que as diferenciações de um momento anterior e a emergência da nova condição ou situação provocam a perda do equilíbrio já estabelecido e o restabelecimento de um novo equilíbrio, com base na condição que emerge. Esses períodos caracterizam as transições no desenvolvimento ou, usando uma terminologia própria da abordagem sistêmica da família, as crises normativas.

Na perspectiva do desenvolvimento no curso de vida, a família passa por diferentes fases, tendo, em cada uma, que realizar tarefas específicas daquela fase (Dessen \& Braz, 2005a; Kreppner, 2003; Stratton, 2003). Com o intuito de compreender as mudanças no ciclo de vida familiar, Carter e McGoldrick (1980/1995) propuseram estágios de desenvolvimento familiar, com base em peculiaridades da classe média dos Estados Unidos, que têm sido referência na literatura internacional e brasileira. Apesar de essa proposta ser restrita à família nuclear tradicional americana das primeiras décadas da segunda metade do século $X X$, não devendo ser generalizada para todos os tipos de famílias e culturas, ela possibilita melhor compreensão do funcionamento familiar e apresenta um panorama das famílias naquela ocasião. Em se tratando do estudo de Pasquali, as famílias de origem da maioria dos jovens universitários vivenciavam o final do quarto estágio de desenvolvimento familiar, período em que transformações no sistema giram em torno do adolescer dos filhos. Nessa fase, os jovens, no pico de sua construção de identidade, questionavam diversas regras, valores e crenças anteriormente estabelecidos 
no relacionamento com os pais e no contexto social e cultural em que estavam inseridos. Como a família vivencia essas experiências com os adolescentes, a sua principal tarefa, nesse momento, é o aumento da flexibilidade nas interações entre os genitores e os filhos adolescentes e, em consequência, uma diminuição da autoridade dos primeiros.

O momento de transição para a adolescência traz consigo a expectativa de mudanças nos padrões de comunicação familiares, pois contrapõe o indivíduo à necessidade de autoafirmação e de desenvolvimento de um novo senso de si mesmo (Kreppner, 2002). Se os respondentes do Questionário de Pai Ideal - QPI da pesquisa de Pasquali estivessem no quinto estágio do desenvolvimento familiar, as suas concepções de pai e de mãe seriam diferentes? Embora só possamos especular a respeito, é provável que sim. No estágio seguinte, o funcionamento familiar gira em torno de proporcionar os recursos e o suporte necessário para que os filhos se tornem independentes e construam seus espaços pessoais e profissionais, dando prosseguimento à trajetória do curso de vida familiar. A tarefa básica desse período é encaminhar os filhos e buscar a reestruturação do relacionamento conjugal.

Apesar de a proposta de Carter e McGoldrick não incluir características próprias das formas alternativas de família, como estruturas monoparentais, famílias recasadas e outras formas de família bem como as especificidades dos diferentes contextos socio-históricoculturais, ela ilustra a interconexão entre o desenvolvimento do grupo familiar e o desenvolvimento do indivíduo. É durante os períodos de mudança no desenvolvimento dos indivíduos que novas necessidades e demandas têm que ser integradas ao estilo e ao conjunto de regras da família, ocorrendo, então, transformações em todo o grupo familiar (Kreppner, 2000).
A descrição de estágios do curso de vida familiar nos aproxima de realidades importantes do processo de desenvolvimento familiar, definindo características próprias de cada período e elucidando as tarefas de desenvolvimento, tanto da família como de seus membros em particular, além de enfatizar os problemas próprios de cada fase. Embora essa noção de tarefas de desenvolvimento familiar date dos primórdios da metade do século XX (Duvall, 1962), ganhou espaço na agenda dos pesquisadores brasileiros muito tempo depois da publicação do artigo de Pasquali, sendo, atualmente, considerada útil também para a identificação de mudanças sociais (Cerveny \& Berthoud, 1997).

\section{Considerações finais}

Muitas são as questões que precisam ser (re) investigadas face às mudanças ocorridas nos últimos 30 anos, a fim de propiciar melhor compreensão do funcionamento familiar. E, por mais simples que seja a questão a ser respondida, o pesquisador é obrigado, atualmente, a reconhecer que a família é um sistema complexo, composto por subsistemas integrados e interdependentes, que estabelece uma relação bidirecional e de mútua influência com o contexto no qual está inserida (Minuchin, 1988). Isso significa que as pesquisas precisam incorporar em sua metodologia as interrelações que os membros familiares mantêm entre si e a integração do sistema familiar ao contexto social, histórico e cultural.

Em função de influências recebidas de diferentes campos do saber, como a Sociologia, a Psicologia e a Antropologia, as tendências atuais têm focalizado construções teóricas e metodológicas mais complexas, que se contrapõem a uma visão reducionista dos fenômenos estudados; portanto, se quisermos entender as interrelações 
entre família, desenvolvimento e cultura, é preciso, conforme salienta Kreppner (2003): (a) direcionar o foco de análise não para as pessoas, individualmente, mas para as relações, (b) compreender que a qualidade emocional da comunicação entre o cuidador e a criança é uma das bases para se estabelecer o funcionamento de uma relação e uma cultura de comunicação comum em uma família, (c) ter em mente que a rede completa de relações de uma família deve ser focalizada, particularmente quando são investigadas influências contextuais nos estágios de desenvolvimento da criança.

A definição ecopsicológica de família proposta por Petzold abarca a maior parte das formas de famílias existentes na atualidade, sem produzir preconceito ou exclusão em relação a esse ou àquele tipo de família. No entanto, a sua definição é teórica, e, apesar de ressaltar critérios de intimidade e intergeracionalidade na constituição de família, estes não são devidamente enfatizados ou considerados do ponto de vista empírico. Tendo em vista os diferentes arranjos familiares presentes nas sociedades ocidentais contemporâneas, é fundamental que os pesquisadores envidem esforços para produzir conhecimento sobre as etapas evolutivas do grupo familiar, diferenciadas por tipologias de famílias. $\mathrm{O}$ que significa, por exemplo, crescer em um lar com apenas um genitor? No passado, a existência de famílias constituídas por um genitor decorria, geralmente, da morte do pai, enquanto hoje a maioria delas é resultante de divórcio. O divórcio, por sua vez, introduziu novos componentes no funcionamento das famílias, cujas consequências e implicações para o desenvolvimento de crianças e adolescentes não são, ainda, conclusivas (Erel \& Burman, 1995). Segundo Stratton, essa área de investigação é complexa, uma vez que as famílas divorciadas ou que optaram por ter filhos sem um companheiro (genitor solteiro) enfrentam problemas que estão associados a desvantagens econômicas. Essas desvantagens exigem do pai ou da mãe um consumo de energia e tempo muito maiores, não só no trabalho, a fim de aumentar a renda familiar, como em casa, no que tange às atividades domésticas. Em outras palavras, o genitor tem pouco tempo para estar com a(s) criança(s), além do estresse e do cansaço provenientes dessa situação peculiar, o que pode prejudicar a qualidade das relações parentais.

Pensar em desenvolvimento humano significa pensar no estabelecimento de relações que o indivíduo mantém com seus contextos proximais, isto é, a família, o local de trabalho ou estudo, sua comunidade, e com os contextos distais, como os valores, as crenças, a cultura. Os avanços ocorridos na ciência do desenvolvimento humano, particularmente na última década do século XX e na área da Psicologia da família (Dessen \& Costa Junior, 2005), colocam em pauta a urgência de se estudar as diferentes composições de família, pois pouco sabemos a respeito de sua funcionalidade e das implicações para o desenvolvimento do indivíduo, em diferentes etapas do curso de vida e em diferentes culturas.

De acordo com Kreppner (2000, 2003), os padrões de comunicação são construídos nas relações estabelecidas pelos indivíduos no contexto da família, com base na cultura familiar ou na cultura das relações familiares. Cultura familiar refere-se a "um conjunto de regras tradicionais, implícitas e explícitas, valores, ações e ambientes materiais que são transmitidos pela linguagem, símbolos e comportamentos, por um grupo de pessoas que interage de forma duradoura" (Saami, Mumme, \& Campos, 1998, citados por Kreppner, 2003, p. 208).

Assim, dada a importância das relações familiares para o entendimento do processo de desenvolvimento humano, 
reitero a necessidade de os pesquisadores concentrarem esforços no estudo das interrelações entre os processos familiares $\mathrm{e}$ os processos de desenvolvimento humano. Um dos caminhos promissores é conhecer o sistema de valores e crenças das famílias, incluindo as concepções, tanto ideais como reais, de todos os seus membros, sobretudo dos genitores e dos filhos, a respeito de família, mãe, pai, irmão, etc. Esse sistema é o mediador do processo de socialização que introduz o indivíduo no mundo objetivo de uma sociedade, ensinando-lhe normas, regras e valores que são pertinentes à vida em comunidade (Gomes, 1992). Nesse processo de socialização, a família transmite significados e fornece uma base contínua para a agregação de conhecimentos comuns ao longo das gerações, constituindo um nicho ecológico que oferece sobrevivência e socialização para a geração seguinte (Kreppner, 2000). Os valores associados aos papéis de pai e mãe estão entre os indicadores mais importantes dos modos de vida das famílias, em diferentes países (Georgas, Berry, \& Kağitçibaşi, 2007).
Diante do exposto, fica o desafio para se investigar os processos familiares visando a conhecer as diferentes modalidades de famílias que estão se constituindo e suas implicações para a trajetória de vida da pessoa em desenvolvimento. O artigo de Pasquali apresenta e discute a concepção ideal de pai e de mãe característica do final da década de 70. Considerando as transformações, tanto no âmbito da estrutura e do funcionamento familiar como no âmbito dos pressupostos norteadores da pesquisa científica, é fundamental investigar novamente essas concepções, contrastando-as, agora, com as de pai e mãe real, de modo que possamos conhecer o que pensa a geração do início do século XXI. Sabemos pouco, ou quase nada, sobre as famílias no Brasil, e pesquisar tais concepções com um novo olhar, com o olhar sistêmico e da interdisciplinaridade, trará contribuições valiosas para a Psicologia da família e do desenvolvimento humano. 


\section{Maria Auxiliadora da Silva Campos Dessen}

Graduação em Bacharel e Licenciatura em Psicologia, mestrado em Psicologia pela Universidade de Brasília e doutorado em Psicologia (Psicologia Experimental). Professora Associada II da Universidade de Brasília E-mail: dessen@unb.br

\section{Endereço para correspondência:}

Laboratório de Desenvolvimento Familiar - LABFAM

Campos da Universidade de Brasília, DF - Brasil CEP 70910-900 


\section{Referências}

Almeida, A. M. (1987). Pensando a família no Brasil: da colônia à modernidade. Rio de Janeiro: Espaço e Tempo.

Arriagada, I. (2000). Nuevas famílias para um nuevo siglo? (Relatório publicado pela Comisión Econômica para América Latina y el Caribe). Chile: CEPAL.

Biasoli-Alves, Z. M. M. (1997). Famílias brasileiras do século XX os valores e as práticas da educação da criança. Temas em Psicologia, 3, 33-49.

Biasoli-Alves, Z. M. M. (2000). Continuidades e rupturas no papel da mulher brasileira no século XX. Psicologia: Teoria e Pesquisa, 16, 233-239.

Bronfenbrenner, U. (1996). A ecologia do desenvolvimento humano: experimentos naturais e planejados (M. A.Veríssimo, trad.). Porto Alegre: Artes Médicas. (Trabalho original publicado em 1979)

Carter, B., \& McGoldrick, M. (Orgs.). (1995). As mudanças no ciclo de vida familiar: uma estrutura para a terapia familiar (M. A.V. Veronese, trad.). Porto Alegre: Artes Médicas. (Trabalho original publicado em 1980)

Cerqueira-Silva, S., Oliveira, N. R., \& Dessen, M. A. (2010). A dinâmica das famílias brasileiras em foco: passado e presente. In M. A. Dessen (Org.), Desenvolvimento familiar no curso de vida. Manuscrito em preparação.

Cerveny, C. M. O., \& Berthoud, C. M. E. (Orgs.). (1997). Família e ciclo vital: nossa realidade em pesquisa. São Paulo: Casa do Psicólogo.

Chaves, U. H. (1997). Família e parentalidade. In C. M. O. Cerveny \& C. M. E. Berthoud, (Orgs.), Família e ciclo vital: nossa realidade em pesquisa (pp. 47-62). São Paulo: Casa do Psicólogo.

Dessen, M. A. (1997). Desenvolvimento familiar: transição de um sistema triádico para poliádico. Temas em Psicologia, 3, 51-61.

Dessen, M. A., \& Biasoli-Alves, Z. M. M. (2001). O estudo da família como base para a promoção da tolerância. In Z. M. M. Biasoli-Alves \& R. Fischmann (Orgs.), Crianças e adolescentes: construindo uma cultura da tolerância (pp. 183-193). São Paulo: Edusp.
Dessen, M. A., \& Braz, M. P. (2000). Rede social de apoio durante transições familiares decorrentes do nascimento de filhos. Psicologia: Teoria e Pesquisa, 16, 221-231.

Dessen, M. A., \& Braz, M. P. (2005a). A família e suas inter-relações com o desenvolvimento humano. In M. A. Dessen \& A. L. Costa-Júnior (Orgs.), A ciência do desenvolvimento humano: tendências atuais e perspectivas futuras (pp. 113-131). Porto Alegre: Artmed.

Dessen, M. A., \& Braz, M. P. (2005b). As relações maritais e sua influência nas relações parentais: implicações para o desenvolvimento da criança. In M. A. Dessen \& A. L. Costa-Júnior (Orgs.), A ciência do desenvolvimento humano: tendências atuais e perspectivas futuras (pp. 132-149). Porto Alegre: Artmed.

Dessen, M. A., \& Costa Junior, A. L. (Orgs.). (2005). A ciência do desenvolvimento humano: tendências atuais e perspectivas futuras. Porto Alegre: Artmed.

Dessen, M. A., \& Torres, C. (2002). Family and socialization factors in Brazil: An overview. In W. J. Lonner, D. L. Dinnel, S. A. Hayes \& D. N. Sattler (Eds.), On line readings in psychology and culture (Unit 13, Chapter 2). Bellingham, Washington: Western Washington University, Center for Cross-Cultural Research. Recuperado em 12 de setembro de 2009, de www. ac.wwu.edu/ culture/DennenTorres.htm

Deutsch, F. M. (2009). Egalitarian relationships. In H. Reis \& S. Sprecher (Eds.), Encyclopedia of Human Relationships (pp. 482-483). Londres: Sage.

Duvall, E. M. (1962). Family development (2a ed., rev.). New York: Lippincott.

Erel, O., \& Burman, B. (1995). Interrelatedness of marital relations and parent-child relations: A meta-analytic review. Psychological Bulletin, 118, 108-132.

Galano, M.M. (2006). Família e história: a história da família. Em C. M. Cerveny e C. M. E. Berthoud, (Orgs.), Família e ciclo vital: nossa realidade em pesquisa (pp. 115-148). São Paulo: Casa do Psicólogo. 
Georgas, J. (2003). Family: Variations and changes across cultures. In W. J. Lonner, D. L. Dinnel, S. A. Hayes \& D. N Sattler (Eds.), Online readings in psychology and culture (Unit 13, Chapter 3). Bellingham, Washington. Recuperado em 4 de abril de 2010, dehttp://www.wwu.edu/culture

Georgas, J., Berry, J. W., \& Kagitçibasi, Ç. (2007). Synthesis: How similar and how different are families across cultures? In J. Georgas, J. W. Berry, F. J. R. van de Vijver, Ç. Kagitçibasi \& Y. H. Poortinga (Eds.), Families across cultures: A 30-nation psychological study (pp. 186-240). Cambridge: Cambridge University Press.

Gomes, J. V. (1992). Família e socialização. Psicologia USP, 3, 93-105.

Gomes, A. J. S., \& Resende, V. R. (2004). O pai presente: o desvelar da paternidade em uma família contemporânea. Psicologia: Teoria e Pesquisa, 20, 119-125.

Henderson, D. A., Tickmyer, A. R., \& Tadlock, B. L. (2005). The impact of welfare reform on the parenting of women in rural communities. Journal of Children \& Poverty, 11, 131-147.

Instituto Brasileiro de Geografia e Estatística. (2006). Síntese de indicadores sociais. Recuperado em 08 de fevereiro de 2009 de http://www.ibge.com.br/

Instituto Brasileiro de Geografia e Estatística (2007). Síntese de indicadores sociais. Recuperado em 27 de outubro de 2009 de http://www.ibge.gov.br/

Kreppner, K. (1992). Developing in a developing context: Rethinking the family's role for children's development. In L. T. Winegar \& J. Valsiner (Eds.), Children's development within social context (pp. 161-179). Hillsdale: Lawrence Erlbaum.

Kreppner, K. (2000). The child and the family: Interdependence in developmental pathways. Psicologia: Teoria e Pesquisa, 16, 11-22.

Kreppner, K. (2003). Social relations and affective development in the first two years in family contexts. In J. Valsiner \& K. J. Connolly (Eds.), Handbook of developmental psychology (pp. 194-214). Londres: Sage.

Lewis, C., \& Dessen, M. A. (1999). O pai no contexto familiar. Psicologia: Teoria e Pesquisa, 15, 09-16.

Minuchin, P. (1988). Relationships within the family: A systems perspective on development. In R. A. Hinde \& J. StevensonHinde, Relationships within families: Mutual influences (pp. 7-26). Oxford-UK: Clarendon Press.

Monteiro, M. F. G. (1998). Saúde reprodutiva. In S. M Kaloustian (Org.), Família brasileira: a base de tudo (pp. 172-183). São Paulo: Cortez.

Neder, G. (1998). Ajustando o foco das lentes: um novo olhar sobre a organização das famílias no Brasil. In S. M. Kaloustian (Org.), Família brasileira: a base de tudo (pp. 26-46). São Paulo: Cortez.

Nolasco, S. (2001). Cultura brasileira, patriarcado e gênero. In Z. M. M. Biasoli-Alves \& R. Fischmann (Orgs.), Crianças e adolescentes: construindo uma cultura da tolerância (pp. 95-107). São Paulo: EDUSP.

Pasquali, L. (1980). Concepção de pais: um instrumento fatorial. Psicologia: Ciência e Profissão, 1, 141-214.

Pereira, P. (2003, 12 de dezembro). A nova família. Revista Época.
Petzold, M. (1996). The psychological definition of "the family". In M. Cusinato (Ed.), Research on family: Resources and needs across the world (pp. 25-44). Milão: LED-Edicioni Universitarie.

Petrucelli, J. L. (1998). Nupcialidade. In S. M. Kaloustian (Org.), Família brasileira: a base de tudo (pp. 159-171). São Paulo: Cortez.

Prado, A. B., Piovanotti, M. R. A., \& Vieira, M. L. (2007). Concepções de pais e mães sobre o comportamento paterno real e ideal. Psicologia em Estudo, 12, 41-50.

Ribeiro, R. M., Sabóia, A. L., Branco, C. H., \& Bregman, S. (1998). Estrutura familiar: trabalho e renda. In S. M. Kaloustian (Org.), Família brasileira: a base de tudo (pp. 135-158). São Paulo: Cortez.

Santos, M. C., Caldana, R. H., \& Biasoli-Alves, Z. M. (2001). O papel masculino dos anos quarenta aos noventa: transformações no ideário. Paidéia, 11, 57-68.

Simionato-Tozo, S. M. P., \& Biasoli-Alves, Z. M. M. (1998). O cotidiano e as relações familiares em duas gerações. Cadernos de Psicologia e Educação Paidéia, 8, 137-150.

Singly, F. (2000). O nascimento do "indivíduo individualizado" e seus efeitos na vida conjugal e familiar. In C. E. Peixoto, F. Singly \& V. Cicchelli (Orgs.), Família e individualização (pp. 13-19). Rio de Janeiro: Editora FGV.

Stratton, P. (2003). Contemporary families as contexts for development. In J. Valsiner \& K. Connolly (Eds.), Handbook of developmental psychology (pp. 333-357). Londres: Sage.

Torres, C., \& Dessen, M. A. (2007). The Brazilian jeitinho: Brazil's sub-cultures, its diversity of social contexts, and its family structures. In J. Georgas, J. W. Berry, F. J. R. van de Vijver, C.. Kağitçibaşi \& Y. H. Poortinga (Eds.), Families across cultures: A 30-nation psychological study (pp. 259-266). Cambridge: Cambridge University Press.

Trindade, H. (2001). As universidades frente à estratégia do governo. In H. Trindade (Org.), Universidade em ruínas: na república dos professores (pp. 27-37). Petrópolis, RJ: Vozes.

Vaitsman, J. (1994). Flexíveis e plurais: identidade, casamento e família em circunstâncias pós-modernas. Rio de Janeiro: Rocco.

Vieira, F. B. (1998). Verso e reverso das mudanças nas famílias de camadas médias no DF. Dissertação de Mestrado, Universidade de Brasília, Brasília, DF.

Wagner, A., Predebon, J., \& Falcke, D. (2005). Transgeracionalidade e educação: como se perpetua a família? In A. Wagner (Org.), Como se perpetua a família? A transmissão dos modelos familiares (pp. 93-106). Porto Alegre: EDIPUCRS.

Wagner, A., Predebon, J., Mosmann, C., \& Verza, F. (2005). Compartilhar tarefas? Papéis e funções de pai e mãe na família contemporânea. Psicologia: Teoria e Pesquisa, 21, 181-186.

Zamberlan, M. A. T., \& Biasoli-Alves, Z. M. M. (Orgs.). (1997). Interações familiares: teoria, pesquisa e subsídios à intervenção. Londrina: Editora da UEL. 